\title{
PsCor413pm2, a Plasma Membrane-Localized, Cold-Regulated Protein from Phlox subulata, Confers Low Temperature Tolerance in Arabidopsis
}

\author{
Aimin Zhou ${ }^{1,+}{ }^{\mathbb{D}}$, Enhui Liu ${ }^{1, \dagger}, \mathrm{He} \mathrm{Li}^{1}{ }^{\text {, Yang Li }}{ }^{1}$, Shuang Feng ${ }^{2}$, Shufang Gong ${ }^{1}$ and \\ Jingang Wang ${ }^{1, *}$ \\ 1 College of Horticulture and Landscape Architecture, Northeast Agricultural University, Harbin 150030, \\ China; aiminzhou@neau.edu.cn (A.Z.); liuenhui1024@aliyun.com (E.L.); 18845798249@163.com (H.L.); \\ liyang44@ibcas.ac.cn (Y.L.); shufanggong@neau.edu.cn (S.G.) \\ 2 Key Laboratory of Saline-Alkali Vegetation Ecology Restoration in Oil Field (SAVER), Ministry of Education, \\ Alkali Soil Natural Environmental Science Center (ASNESC), Northeast Forestry University, Harbin 150040, \\ China; shuangfeng1986@aliyun.com \\ * Correspondence: wangjingang99@neau.edu.cn; Tel.: +86-451-5519-0743 \\ + The authors contributed equally to this work.
}

Received: 10 August 2018; Accepted: 27 August 2018; Published: 30 August 2018

check for updates

\begin{abstract}
Low temperature stress adversely affects plant growth and development. Isolation and characterization of cold response genes from cold-tolerant plants help to understand the mechanism underlying low temperature tolerance. In this study, PsCor413pm2, a cold-regulated (COR) gene isolated from Phlox subulata, was transferred to Arabidopsis plants to investigate its function. Real-time quantitative PCR analysis revealed that Ps Cor413pm2 expression was induced by cold. Subcellular localization revealed that the PsCor413pm2-green fluorescent protein (GFP) fusion protein localized to the plasma membrane in tobacco and Arabidopsis plants. Furthermore, overexpression of PsCor $413 \mathrm{pm} 2$ in Arabidopsis plants enhanced tolerance to low temperature stress. Transgenic Arabidopsis roots had more influx of $\mathrm{Ca}^{2+}$ after a cold shock than wild-type plants, as shown using non-invasive micro-test technology (NMT). Moreover, the transcription abundance of five COR and two C-repeat (CRT) binding factor (CBF) genes in transgenic Arabidopsis plants was higher than that in the wild-type plants under cold stress. Taken together, our results suggest that overexpression of $P_{s}$ Cor $413 \mathrm{pm} 2$ enhances low temperature tolerance in Arabidopsis plants by affecting $\mathrm{Ca}^{2+}$ flux and the expression of stress-related COR and CBF genes.
\end{abstract}

Keywords: cold stress; cold-regulated gene; Phlox subulata; PsCor413pm2; transgenic Arabidopsis

\section{Introduction}

Low temperatures adversely affect plant growth, development, and crop productivity [1]. During the process of long-term adaptive evolution, some temperate plant species have evolved a series of physiological and molecular mechanisms to acclimate to low temperatures. Among these mechanisms, cold signaling pathways dependent on $\mathrm{C}$-repeat binding factors (CBFs) are the best-understood regulatory pathways involved in cold acclimation [2,3].

Cold stress is sensed by membrane proteins, leading to a cytosolic $\mathrm{Ca}^{2+}$ signal. $\mathrm{Ca}^{2+}$-binding proteins may mediate the $\mathrm{Ca}^{2+}$ signal to activate a series of downstream transcription factors, such as inducer of CBF expression 1 (ICE1), which is the upstream regulator of CBF. CBF proteins can bind to C-repeat (CRT) cis-elements and activate transcription of the downstream cold-regulated (COR) genes to increase cold tolerance [1,4-6]. Studies have shown that expression of COR genes is positively correlated with cold tolerance in plants [7-10]. COR genes, such as Cor6.6, Cor15, Cor47, Cor78, 
and Cor413 have been identified in Arabidopsis plants [11-13]. Among these genes, AtCor15 and AtCor78 are the most characterized. Reports have shown that AtCor15 is a chloroplast stromal protein that protects chloroplast membranes during freezing stress [14-16]. Further, AtCor78, also known as $A t R D 29 A$ (responsive to dehydration, RD), is involved in the response to cold, dehydration, and salt stressors [17-19].

The Cor413 family of proteins has been divided into two distinct groups, including Cor413-plasma membrane (Cor413pm) and Cor413-inner membrane (Cor413im) proteins [13]. Studies have shown that Arabidopsis AtCor413im localizes to the inner membrane of chloroplasts and may stabilize the chloroplast membrane under cold stress [20,21]. However, Cor413pm localization to the plasma membrane and its functions in response to cold stress have not been reported. Recently, we characterized the functions of PsCor413im1 from Phlox subulata, which are cold-tolerant plants. Overexpression of PsCor413im1 enhanced cold tolerance in Arabidopsis plants [22]. Here, we identified PsCor413pm2 as another member of the Cor413 family and conducted a preliminary evaluation of its functions using transgenic Arabidopsis plants. Subcellular localization of PsCor413pm2 was performed using GFP as a marker. Using non-invasive micro-test technology (NMT), we then measured the effects of PsCor413pm 2 overexpression on $\mathrm{Ca}^{2+}$ flux in Arabidopsis roots under cold shock. Our study helps to further characterize the function of Cor413 proteins.

\section{Results}

\subsection{Sequence Analysis of PsCor413pm2}

The full-length PsCor413pm2 cDNA contained a 609-bp open reading frame (ORF), which was predicted to encode a protein of 202 amino acids with a molecular mass of $22.07 \mathrm{kDa}$. Multiple sequence alignment and phylogenetic analyses revealed that PsCor413pm2 is highly homologous to two members of the Cor413pm protein family from other plant species $(>77.11 \%$ identity), including Arabidopsis thaliana, Nicotiana tomentosiformis, Ipomoea nil, Tarenaya hassleriana, Jatropha curcas, and Gossypium hirsutum (Figure 1A,B). PsCor413pm2 was predicted to have five transmembrane domains using the TMHMM algorithm (Figure 1A,C). qPCR analysis showed that PsCor413pm2 expression was obviously induced by cold $\left(4^{\circ} \mathrm{C}\right)$ and mannitol $(300 \mathrm{mM})$ stress and slightly by $\mathrm{NaCl}$ $(150 \mathrm{mM})$ and abscisic acid (ABA) $(100 \mu \mathrm{M})$ (Figure 2). We add it, please confirm.
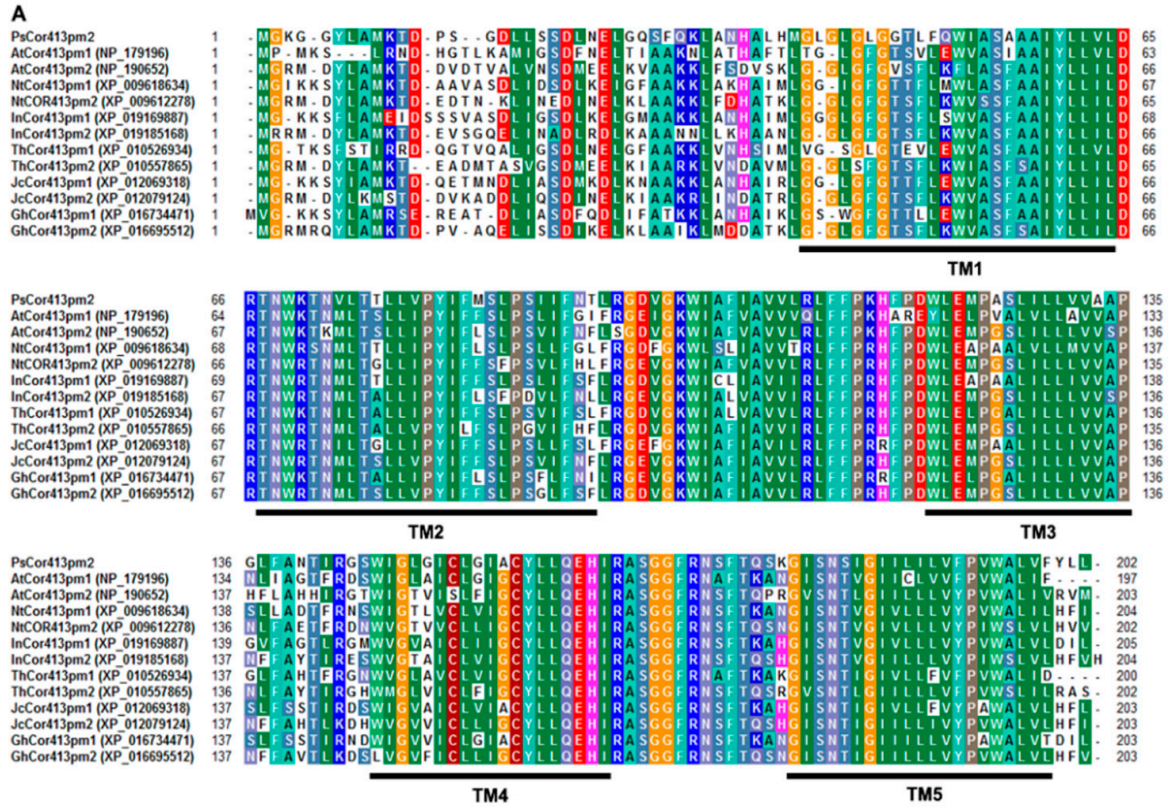

Figure 1. Cont. 
B

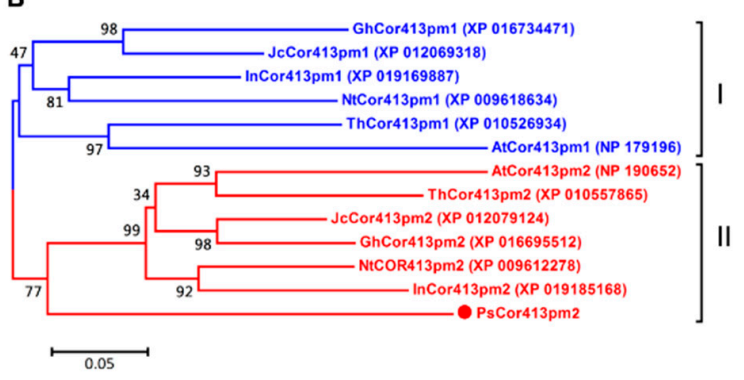

C

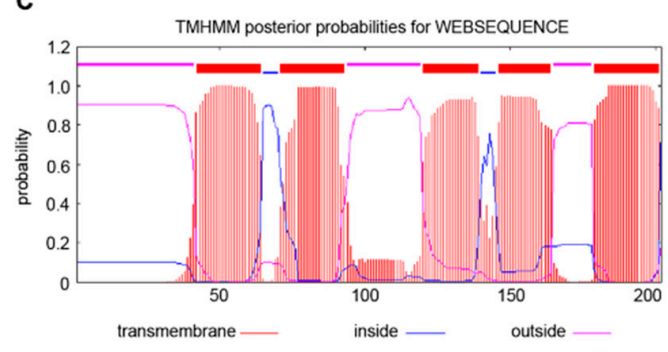

Figure 1. Sequence analysis of PsCor413pm2. Amino acid sequence alignment (A) and phylogenetic tree (B) of PsCor413pm2 with Cor413pm proteins from Arabidopsis thaliana (GenBank accession numbers: NP_179196 and NP_190652), Nicotiana tomentosiformis (XP_009618634 and XP_009612278), Ipomoea nil (XP_019169887 and XP_019185168), Tarenaya hassleriana (XP_010526934 and XP_010557865), Jatropha curcas (XP_012069318 and XP_012079124), and Gossypium hirsutum (XP_016734471 and XP_016695512) are shown. Colored backgrounds indicate identical residues. The black box bars indicate five putative transmembrane (TM) domains. (C) Putative transmembrane domains of PsCor413pm2 are shown.

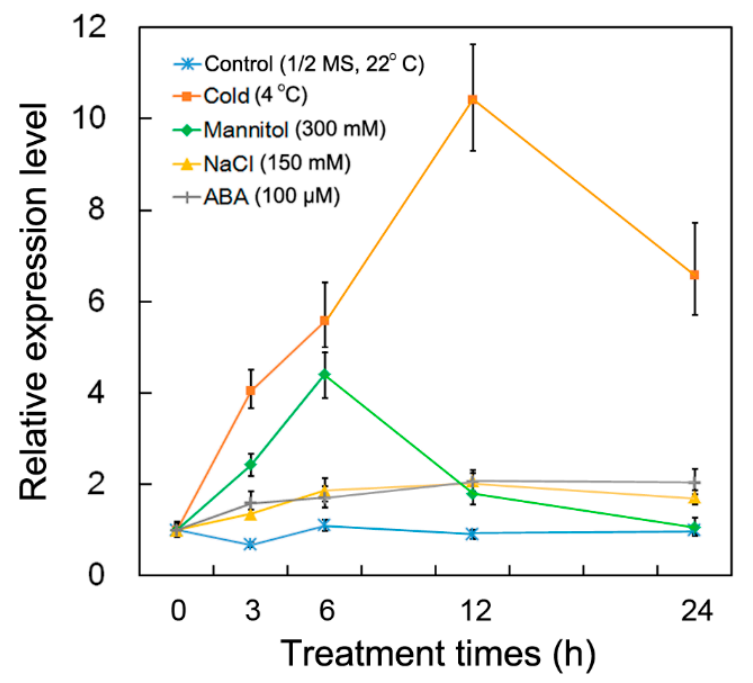

Figure 2. Expression of PsCor413pm2 under multiple stresses. Two-week-old Phlox subulata seedlings were treated with cold $\left(4^{\circ} \mathrm{C}\right)$, mannitol $(300 \mathrm{mM}), \mathrm{NaCl}(150 \mathrm{mM})$, and abscisic acid (ABA) $(100 \mu \mathrm{M})$ for $0,3,6,12$, and $24 \mathrm{~h}$. The PsActin gene was used as an internal control, and the transcript level in the untreated seedlings was set as 1.0. Error bars show the standard deviation (SD) of the values from three replicates.

\subsection{Subcellular Localization of PsCor413pm2}

To confirm whether PsCor413pm2 is a membrane protein, localization of PsCor413pm2 in plant cells was examined using GFP as a fusion protein marker. In tobacco leaf epidermis cells transiently expressing PsCor413pm2-GFP, GFP signals were localized to the cell periphery, which is similar to the plasma membrane (Figure 3A). In Arabidopsis root and root hair cells stably expressing PsCor413pm2-GFP, the GFP signals were also observed in the cell periphery and co-localized with the plasma membrane marker dye FM4-64 (after staining for $1 \mathrm{~min}$ ) (Figure 3B). However, when GFP alone was used as a control, it localized to the cytoplasm in tobacco leaf epidermis and Arabidopsis root hair cells (Figure 3A,B). These results suggest that PsCor413pm2-GFP localized to the plasma membrane. 


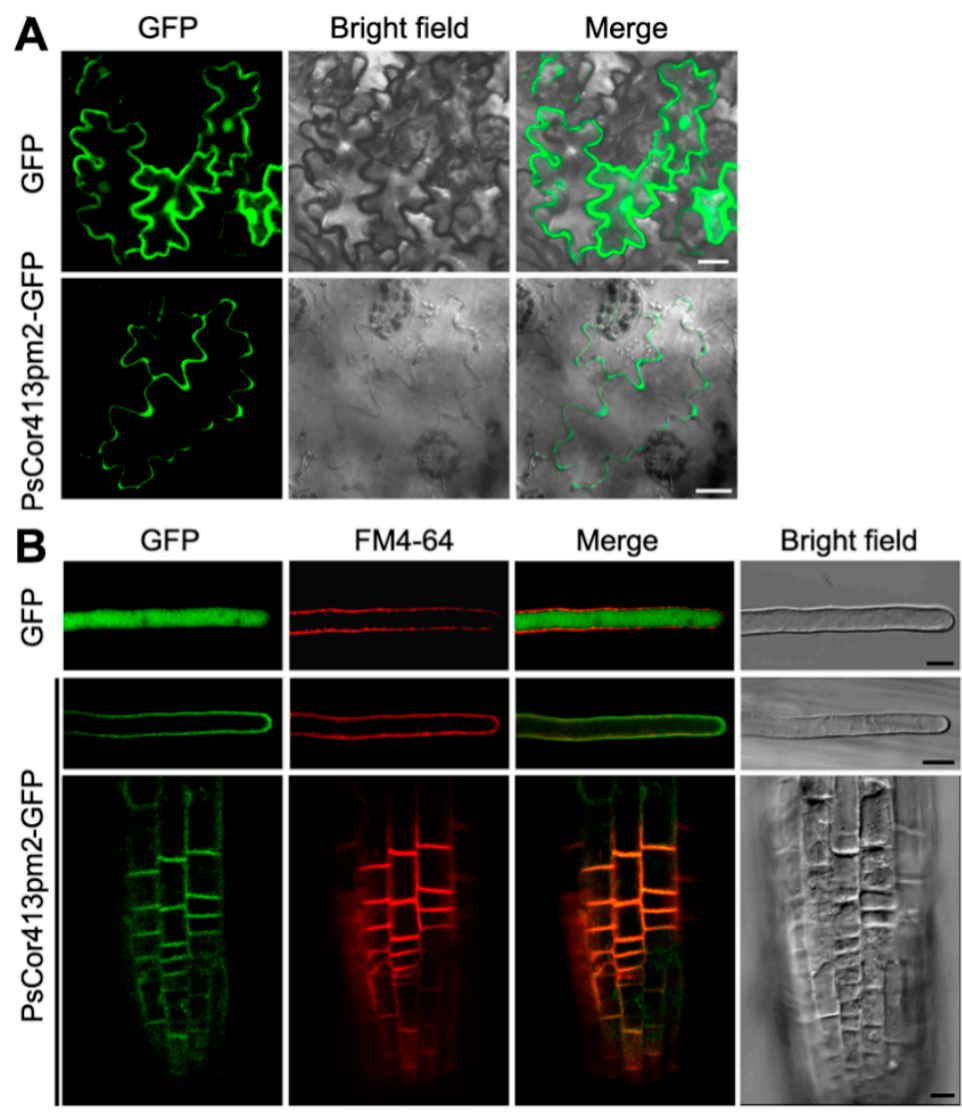

Figure 3. Subcellular localization of PsCor413pm2. (A) Confocal images of tobacco leaf epidermal cells transiently expressing GFP or PsCor413pm2-GFP are shown. (B) Confocal images of Arabidopsis root and root hair cells stably expressing GFP or PsCor413pm2-GFP incubated for 1 min with $4 \mu \mathrm{M}$ FM4-64 are shown. GFP fluorescence is green, and FM4-64 is red. Merge pictures were created by merging the GFP and FM4-64 fluorescent images. Scale bars $=10 \mu \mathrm{m}$.

\subsection{Overexpression of PsCor413pm2 in Arabidopsis Enhances Tolerance to Low Temperature}

Transgenic Arabidopsis plants overexpressing PsCor413pm2 driven by a CaMV35S promoter were generated (Figure $4 \mathrm{~A}$ ) to evaluate its possible role in the plant response to multiple stresses. First, we compared the germination rate of seeds from the transgenic lines and wild type (WT) plants on $1 / 2$ strength Murashige and Skoog (MS) medium under cold $\left(4^{\circ} \mathrm{C}\right)$ stress. At normal temperatures $\left(22^{\circ} \mathrm{C}\right)$, germination rates in the transgenic seeds were similar to those of WT seeds. However, under cold $\left(4^{\circ} \mathrm{C}\right)$ stress conditions, germination rates of the transgenic seeds were significantly higher than those of WT seeds after 18 and 22 days of cultivation (Figure 4B,C). Moreover, we compared the maximum photochemical efficiency $(\mathrm{Fv} / \mathrm{Fm})$ of leaves of transgenic lines and WT plants growing in soil under normal and cold $\left(4{ }^{\circ} \mathrm{C}\right)$ stress (Figure $\left.4 \mathrm{D}\right)$. As shown in Figure $4 \mathrm{E}$, cold $\left(4^{\circ} \mathrm{C}, 48 \mathrm{~h}\right)$ treatment resulted in marked decreases in Fv/Fm in both the WT and transgenic plants, but the Fv/Fm of the transgenic plants (\#10 and \#16) upon stress treatment was higher than that of the WT plants. Further, we compared electrical conductivity (EC) and survival rate of transgenic lines and WT plants growing in soil under normal and freezing $\left(-10^{\circ} \mathrm{C}\right)$ stress. The EC of transgenic plants was significantly lower than that of WT plants after freezing $\left(-10^{\circ} \mathrm{C}\right)$ treatment for $2 \mathrm{~h}$ (Figure $\left.5 \mathrm{~A}, \mathrm{~B}\right)$. The EC results indicated less damage from the freezing treatment in transgenic plant leaves than in WT leaves. Furthermore, the survival rate of transgenic plants was higher than that of WT after freezing $\left(-10^{\circ} \mathrm{C}\right)$ treatment (Figure $\left.5 \mathrm{~A}, \mathrm{C}\right)$. These results suggest that overexpression of $P_{S} \operatorname{Cor} 413 \mathrm{pm} 2$ improves tolerance to low temperature stress in Arabidopsis plants. 
In addition, we compared seedling growth in the transgenic lines and WT plants under osmotic stress. On 1/2 strength MS supplemented with mannitol, germination rate (with $250 \mathrm{mM}$ mannitol), primary root length, and fresh weight (with 175 and $200 \mathrm{mM}$ mannitol) of the transgenic seedlings were significantly greater than those of WT plants (Supplementary Figure S1).
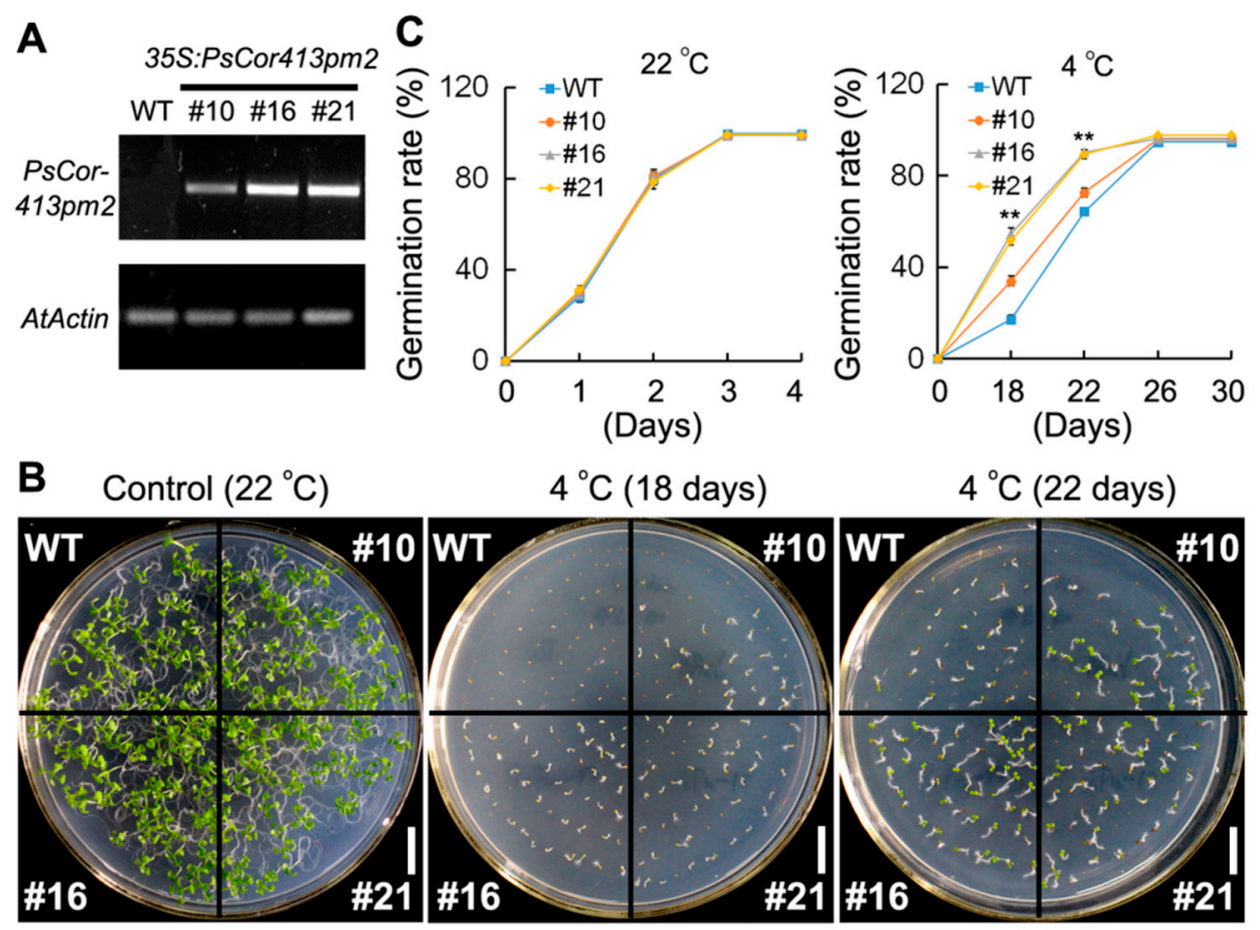

$4{ }^{\circ} \mathrm{C}$ (18 days)

$4{ }^{\circ} \mathrm{C}$ (22 days)
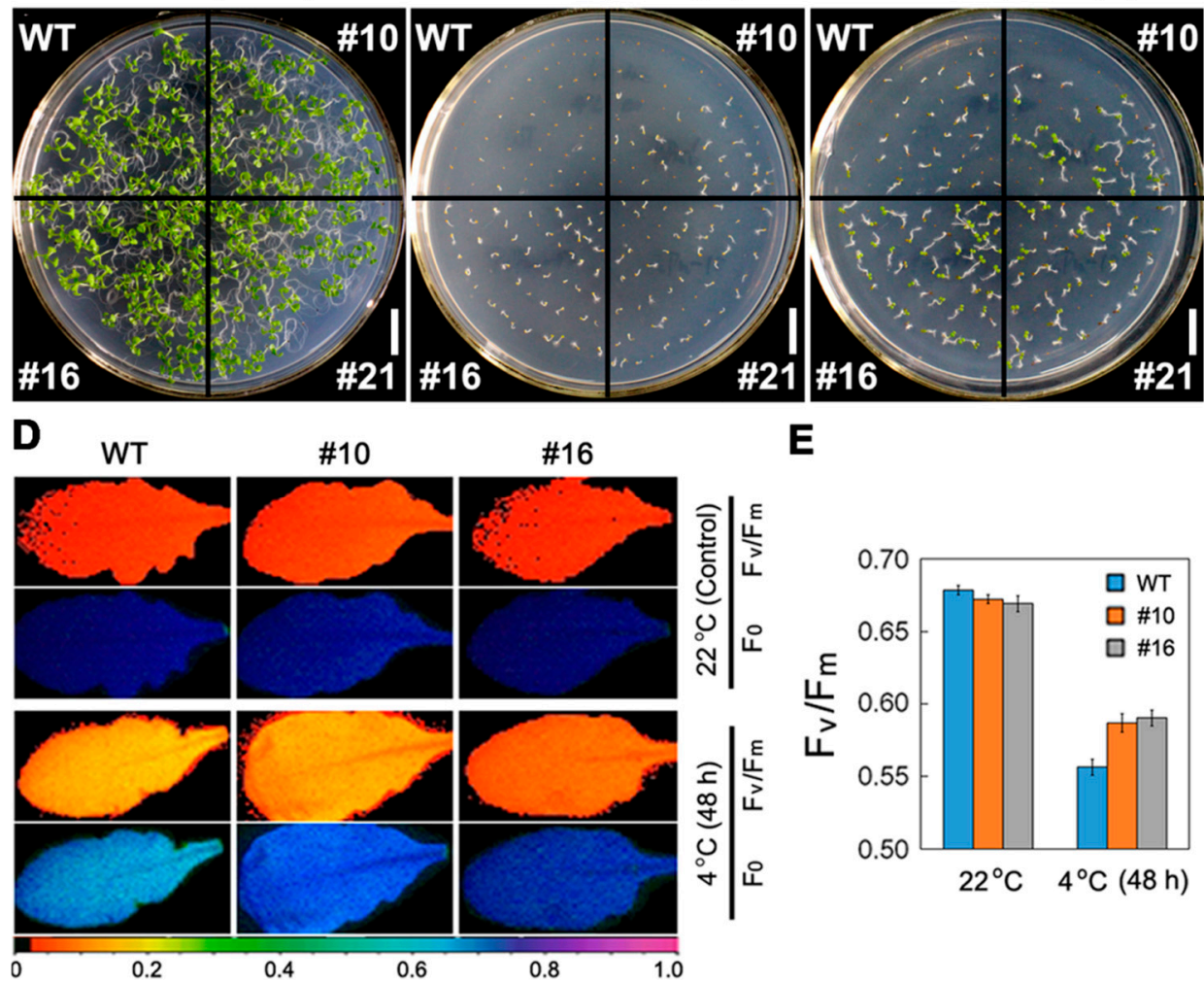

0.4

$$
0.6
$$

Figure 4. Phenotypes of transgenic Arabidopsis and wild type (WT) seedlings under low temperature stress. (A) Semi-quantitative PCR analyses of PsCor413pm2 expression in WT and three transgenic Arabidopsis lines (\#10,\#16, and \#21) overexpressing PsCor413pm2. (B,C) Comparison of germination rates in the WT and three transgenic lines on 1/2 strength Murashige and Skoog (MS) medium under normal $\left(22^{\circ} \mathrm{C}\right)$ and cold $\left(4^{\circ} \mathrm{C}\right)$ stress. Maximal photochemical efficiency $(\mathrm{Fv} / \mathrm{Fm})$ of transgenic Arabidopsis and WT leaves under cold stress. $\mathrm{F}_{0}$ and $\mathrm{Fv} / \mathrm{Fm}$ images (D) and their quantification analysis (E) of leaves of WT and transgenic lines (\#10 and \#16) under normal $\left(22{ }^{\circ} \mathrm{C}\right)$ and cold $\left(4{ }^{\circ} \mathrm{C}, 48 \mathrm{~h}\right)$ stress. The pseudocolored bar depicted at the bottom of the panel ranges from 0 (black) to 1.0 (purple). Asterisks indicate significant differences between WT and transgenic lines (** $p<0.01$; Student's $t$ test). Error bars show standard error (SE) of the values from three replicates. Scale bars $=1 \mathrm{~cm}$. 


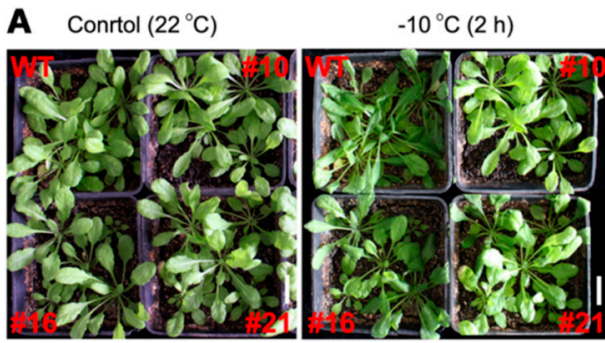

B
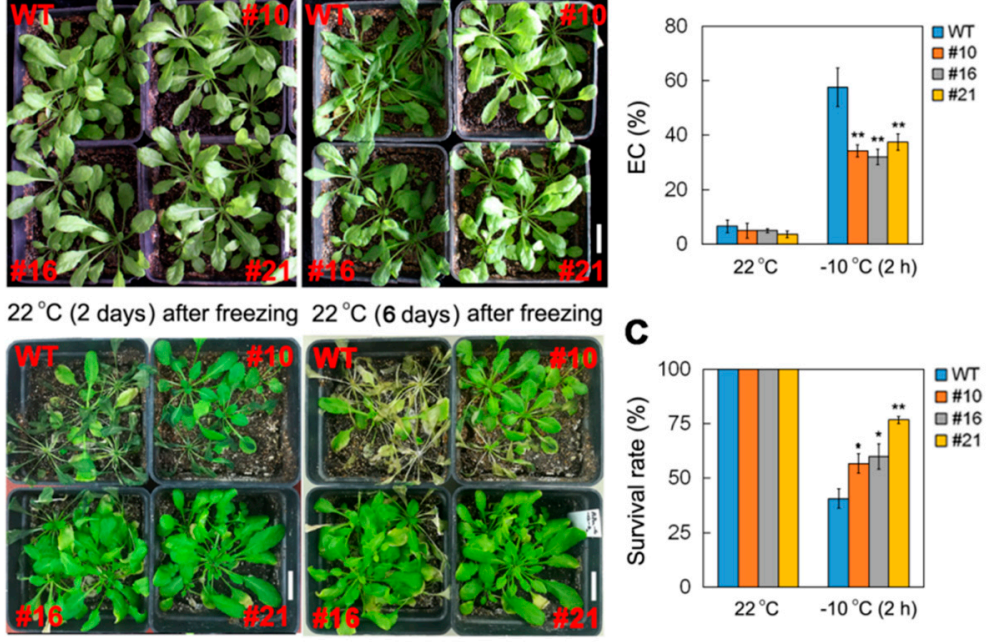

Figure 5. Comparison of phenotype (A), electrical conductivity (EC) (B), and survival rate (C) of WT and transgenic plants grown in soil under normal $\left(22^{\circ} \mathrm{C}\right)$ and freezing $\left(-10^{\circ} \mathrm{C}, 2 \mathrm{~h}\right)$ stress. Asterisks indicate significant differences between WT and transgenic lines $\left({ }^{*} p<0.05\right.$; ${ }^{* *} p<0.01$; Student's $t$ test). Error bars show standard error (SE) of the values from three replicates. Scale bars $=2 \mathrm{~cm}$.

\subsection{Overexpression of PsCor413pm2 in Arabidopsis Affects $\mathrm{Ca}^{2+}$ Flux and Stress-Related Genes Expression}

The initial plant response to cold was confirmed to be an influx of $\mathrm{Ca}^{2+}$ as a signaling molecule into the cytosol through the plasma membrane [1]. Net $\mathrm{Ca}^{2+}$ flux in response to cold shock in seedling roots from transgenic Arabidopsis and WT plants was monitored using NMT (Figure 6A). At normal temperatures $\left(22^{\circ} \mathrm{C}\right)$, there was a significant influx of extracellular $\mathrm{Ca}^{2+}$, with a minus peak in transgenic Arabidopsis and WT roots. Upon cold $\left(4{ }^{\circ} \mathrm{C}\right)$ shock, WT roots exhibited a slight $\mathrm{Ca}^{2+}$ efflux, while transgenic Arabidopsis roots exhibited a greater influx of $\mathrm{Ca}^{2+}$ (Figure 6B). The mean $\mathrm{Ca}^{2+}$ influx in untreated transgenic Arabidopsis roots was slightly higher than that in WT plants. However, there were significant differences in the mean $\mathrm{Ca}^{2+}$ flux attributable to cold shock between transgenic Arabidopsis and WT plants (Figure 6C). These results suggest that overexpression of PsCor413pm2 affects $\mathrm{Ca}^{2+}$ flux in Arabidopsis roots under cold shock.
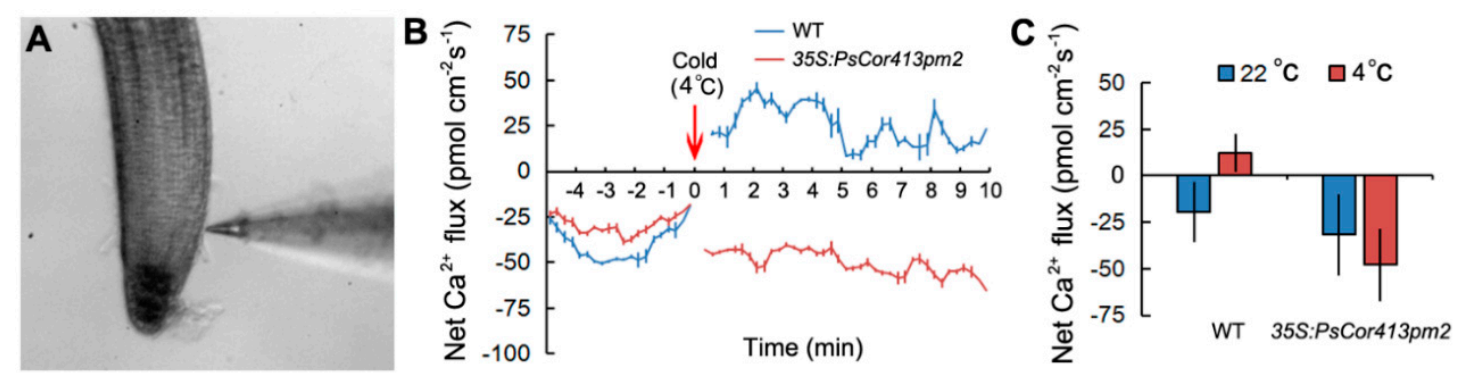

Figure 6. Effect of cold shock on net $\mathrm{Ca}^{2+}$ flux in the root elongation zone of transgenic Arabidopsis and wild type (WT) seedlings. (A) The root zones of Arabidopsis seedlings as measured using non-invasive micro-test technology (NMT). (B) $\mathrm{Ca}^{2+}$ kinetics recorded after a cold $\left(4{ }^{\circ} \mathrm{C}\right)$ solution was added (at red arrow) to the chamber are shown. Prior to the cold shock, $\mathrm{Ca}^{2+}$ fluxes in roots were examined for approximately $5 \mathrm{~min}$ at room temperature $\left(22^{\circ} \mathrm{C}\right)$. (C) The mean $\mathrm{Ca}^{2+}$ flux rate in the root elongation zone of transgenic Arabidopsis plants (\#10) overexpressing PsCor413pm2, as well as WT plants during the period of cold shock is shown. Error bars show the SE of the values from six replicates. 
Further, the expression of five COR genes (AtCor6.6/AtKIN2, AtCor15A, AtCor15B, AtCor47, and $A t C o r 78 / A t R D 29)$ in transgenic Arabidopsis and WT plants was investigated under conditions of cold stress. Under normal and cold $\left(4^{\circ} \mathrm{C}\right)$ conditions, the transcript abundance of these five COR genes in transgenic Arabidopsis plants was evidently higher than in the WT plants (Figure 7A and Supplementary Figure S2A). The expression of many COR genes was regulated by CBF transcription factors. Further, we compared the expression of AtCBFs in transgenic Arabidopsis and WT plants under normal and cold $\left(4{ }^{\circ} \mathrm{C}\right)$ stress. Under cold $\left(4{ }^{\circ} \mathrm{C}\right)$ conditions, AtCBF2 and AtCBF3 expression from the $A t C B F$ gene family was evidently higher than in the WT plants (Figure 7B and Supplementary Figure S2B). These results suggest that overexpression of PsCor413pm2 affects expression of two CBF and five COR genes in Arabidopsis plants under cold stress.

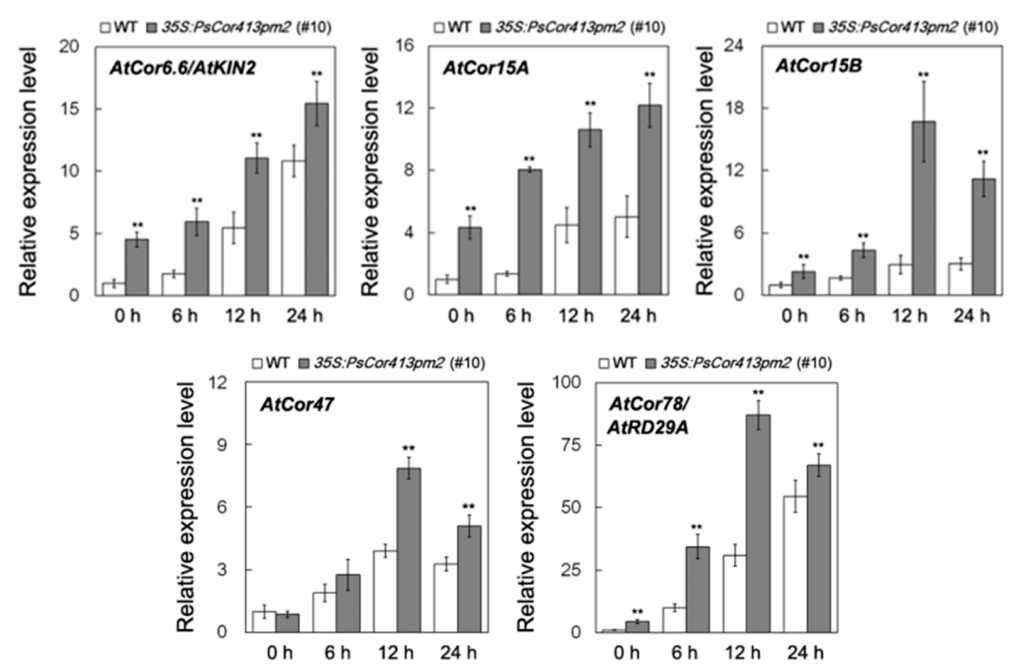

(A)
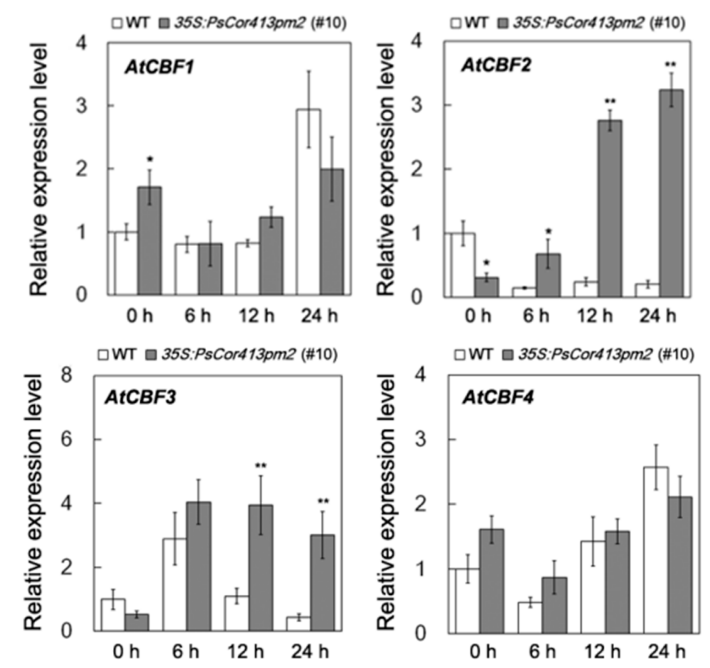

(B)

Figure 7. Expression of stress-associated genes in transgenic Arabidopsis and wild type (WT) seedlings under cold stress. Two-week-old transgenic Arabidopsis line (\#10) overexpressing PsCor413pm2 and WT seedlings were treated at $4{ }^{\circ} \mathrm{C}$ for the indicated time periods. Expression of the AtCor6.6/AtKIN2, AtCor15A, AtCor15B, AtCor47, AtCor78/AtRD29 (A) and AtCBF1 to AtCBF4 (B) genes was investigated using qPCR. The AtActin 2 gene was used as an internal control, and the transcript level in the untreated WT seedlings was set as 1.0. Asterisks indicate significant differences between WT and transgenic lines $\left({ }^{*} p<0.05 ;{ }^{* *} p<0.01\right.$; student's $t$ test). Error bars show the SD of the values from three replicates. 


\section{Discussion}

The CBF pathway activation is an important plant response pathway to low temperature stress. Plants likely sense low temperatures through plasma membrane proteins such as chilling-tolerance-divergence 1 (COLD1), which might induce a cytosolic $\mathrm{Ca}^{2+}$ signal and activate protein kinases [23]. Protein kinases are assumed to activate downstream transcription factors such as calmodulin-binding transcription activators (CAMTAs) and ICE1 through sumoylation and phosphorylation. ICE1-activated CBF regulates the expression of COR genes, which confer low temperature tolerance in plants [1,4-6]. Cor413 is a member of the COR gene family, and it is divided into two groups, Cor413pm and Cor413im. In our study, the presence of a homolog of Cor413pm 2 was revealed in the genome of $P$. subulata. The sequence analysis showed that it might be a conserved membrane protein with five transmembrane domains (Figure 1). qPCR analysis showed that PsCor413pm2 expression was obviously induced by cold and mannitol stress (Figure 2). Similarly, the AtCor413pm2 expression in Arabidopsis was also induced by cold and mannitol stress (data from Arabidopsis eFP Browser). Subcellular localization of GFP as a fusion marker showed that PsCor413pm2-GFP was localized to the plasma membrane in Arabidopsis (Figure 3), indicating that the fusion of GFP did not affect the normal localization of PsCor413pm2. These results suggest that PsCor413pm2 is a cold-regulated protein located on the plasma membrane. Furthermore, seed germination, leaf photochemical efficiency, electrical conductivity, and survival rate analysis showed that PsCor413pm2 transgenic Arabidopsis are more tolerant to low temperatures than WT (Figures 4 and 5). In addition, our study showed that the transcript abundance of five AtCOR (AtCor6.6/AtKIN2, AtCor15A, AtCor15B, AtCor47, and AtCor78/AtRD29) and two AtCBF (AtCBF2 and AtCBF3) genes from PsCor413pm2 transgenic Arabidopsis was significantly higher than that of WT plants under cold stress (Figure 7 and Supplementary Figure S2). These results suggest that overexpression of PsCor413pm 2 in Arabidopsis may confer tolerance to low temperatures by influencing the expression of COR and CBF genes. NMT analysis revealed a greater $\mathrm{Ca}^{2+}$ influx in transgenic Arabidopsis roots under cold shock (Figure 6). Under cold stress, an increase in cytosolic $\mathrm{Ca}^{2+}$ as a signaling molecule activates downstream COR gene expression [24]. Therefore, the influx of $\mathrm{Ca}^{2+}$ may cause an increase in COR gene expression in transgenic Arabidopsis. However, how the overexpression of PsCor413pm 2 affects the flux of $\mathrm{Ca}^{2+}$ is unclear. We speculate that there are two possibilities. Subcellular localization showed that PsCor413pm2 is a plasma membrane protein (Figure 3), and it is known that the plasma membrane is the primary site of chilling and freezing injury. Therefore, the first proposed hypothesis is that PsCor413pm2 may be a plasma membrane protein associated with $\mathrm{Ca}^{2+}$ signaling. Similarly, COLD1, a cold-related protein localized on the plasma membrane in Japonica rice, also affects the flux of $\mathrm{Ca}^{2+}$ in the root under cold shock. Further, researchers have demonstrated that COLD1, as a regulator of G-protein signaling, confers cold tolerance by modulating $\mathrm{Ca}^{2+}$ signaling in rice $[25,26]$. Early studies predicted that Cor413 proteins are G protein-coupled receptors [13]. The second hypothesis is that PsCor413pm2 is a membrane-stabilizing protein. As an integral membrane protein, PsCor413pm2 could play a structural role by stabilizing the plasma membrane lipid bilayer. The stability of the plasma membrane contributes to the function of plasma membrane proteins, such as $\mathrm{Ca}^{2+}$-flux regulating related proteins. The expression of AtCBF2 and AtCBF3 in transgenic Arabidopsis may be affected by the change of $\mathrm{Ca}^{2+}$ flux caused by PsCor413pm 2 overexpression.

In addition, PSCor413pm 2 overexpression enhances tolerance to osmotic stress in Arabidopsis (Supplementary Figure S1). Under normal conditions, the expression of AtCor78 in transgenic plants was significantly higher than that in WT plants (Figure 7 and Supplementary Figure S2A). AtCor78 is also known as AtRD29A, which is involved in plant responses to dehydration stress [27]. Thus, overexpression of PsCor413pm 2 enhances osmotic tolerance in Arabidopsis plants and may be related to the enhanced expression of AtCor78/AtRD29A under normal conditions.

Taken together, our results suggest that overexpression of $P_{s} C o r 413 p m 2$ enhances low temperature tolerance in Arabidopsis plants by affecting $\mathrm{Ca}^{2+}$ flux and the expression of stress-related COR and CBF 
genes. Nevertheless, we will continue to study these mechanisms, as they should be further evaluated and verified.

\section{Materials and Methods}

\subsection{Identification of PsCor413pm2 and Sequence Analysis}

Based on sequence similarity, the PsCor413pm2 gene (GenBank accession number: KT337405.1) was identified using transcriptome sequencing data from cold-treated P. subulata. The amino acid sequences of PsCor413pm2 and its homologs were aligned using ClustalW. The transmembrane domains in PsCor413pm2 were predicted using the TMHMM algorithm [28], and the phylogenetic tree was constructed via the neighbor-joining method using the molecular evolutionary genetics analysis (MEGA) 4.1 software [29] with 1000 bootstrap replicates. The bootstrap scores $<50 \%$ were deleted.

\subsection{Plant Material and Growth Conditions}

P. subulata plants were grown under controlled greenhouse conditions with $70-80 \%$ relative humidity, $14 \mathrm{~h}$ of light, and an average temperature of $22^{\circ} \mathrm{C}$. All Arabidopsis thaliana plants used in this study belonged to the Columbia- 0 ecotype. The seeds were surface sterilized and stratified at $4{ }^{\circ} \mathrm{C}$ for 2 days in the dark. The seedlings were then grown on $1 / 2$ strength MS medium ( $3 \%$ sucrose, $1 \%$ agar, $\mathrm{pH}$ 5.8) under a $12 \mathrm{~h} \mathrm{light} / 12 \mathrm{~h}$ dark photoperiod $\left(100 \mu \mathrm{mol} \mathrm{m}{ }^{-2} \mathrm{~s}^{-1}\right.$ light intensity) at $22{ }^{\circ} \mathrm{C}$.

For abiotic stress treatments, 2-week-old P. subulata or Arabidopsis seedlings were exposed to $4{ }^{\circ} \mathrm{C}$, $100 \mu \mathrm{M} \mathrm{ABA}, 150 \mathrm{mM} \mathrm{NaCl}$, or $300 \mathrm{mM}$ mannitol. At least 10 seedlings from each treatment group were harvested and pooled at different time points $(0,3,6,12$, or $24 \mathrm{~h}$ after treatment), frozen immediately in liquid nitrogen, and stored at $-80^{\circ} \mathrm{C}$ for RNA preparation.

\subsection{RNA Extraction and Real-Time Quantitative PCR ( $q P C R)$ Analyses}

Total RNA was extracted using a RNeasy mini kit (Qiagen, Valencia, CA, USA) according to the manufacturer's instructions. First-strand cDNA was synthesized from $1 \mu \mathrm{g}$ total RNA with the M-MLV RTase cDNA synthesis kit (TaKaRa, Shiga, Japan). Real-time quantitative PCR analysis was performed using the SYBR green mix (Agilent Technologies, Palo Alto, CA, USA) in an optical 96-well plate on a $\mathrm{Mx3000P}$ system (Agilent). Three biological repeats and three technical repeats were performed for qPCR analysis. The primers used in this study are shown in Supplementary Table S1.

\subsection{Vector Construction and Plant Transformation}

To create the pBI121-PsCor413pm2 construct, the ORF of PsCor413pm2 was amplified via PCR and cloned at the $\mathrm{XbaI}$ and SacI sites of the pBI121 vector. To construct the GFP fusion genes, the ORF of PsCor413pm2, without the stop codon, was amplified using PCR and cloned at the XbaI and KpnI sites of the pBI121-GFP vector. The accuracy of the above constructs was confirmed by sequencing, and the specific primers used in this study are shown in Supplementary Table S1.

The constructs were transformed into the Agrobacterium tumefaciens strain EHA105 for plant transformation. Transient expression in tobacco leaves was performed according to a previously described procedure [22]. Arabidopsis plants were transformed using the floral dip method [30]; the transgenic plants were then selected on $1 / 2$ strength MS medium containing $30 \mu \mathrm{g} \mathrm{mL}^{-1}$ kanamycin. Expression of PsCor413pm 2 in the transgenic lines was assessed via semi-quantitative reverse transcription PCR analyses using the T3 generation.

\subsection{Confocal Laser Scanning Microscopy}

The tobacco leaf epidermis was peeled to make a temporary squash and then visualized using confocal laser scanning microscopy (CLSM; Nikon, A1, Tokyo, Japan). Four-day-old Arabidopsis seedlings grown on vertical $1 / 2$ strength MS agar plates were incubated in $1 \mathrm{~mL}$ liquid $1 / 2$ strength MS medium (0.5\% sucrose, pH 5.8) containing $4 \mu \mathrm{M}$ FM4-64 (Invitrogen, Carlsbad, CA, USA) for $1 \mathrm{~min}$ 
at room temperature $\left(22^{\circ} \mathrm{C}\right)$. Roots of transgenic Arabidopsis seedlings were washed twice with liquid $1 / 2$ strength MS medium immediately before visualizing via CLSM. GFP signals were detected using a 500-530 nm emission filter. FM4-64 signals were detected using a 620-680 nm emission filter.

\subsection{Low Temperature and Osmosis Tolerance Assay}

Arabidopsis seeds were treated at $4{ }^{\circ} \mathrm{C}$ for 2 days and then grown on $1 / 2$ strength MS medium at different temperatures $\left(22^{\circ} \mathrm{C}\right.$ or $\left.4{ }^{\circ} \mathrm{C}\right)$ or $1 / 2$ strength MS medium supplemented with mannitol $(0,175,200 \mathrm{mM}$, or $250 \mathrm{mM})$ before measuring seed germination rate, seedling root length, and fresh weight. The experiment was replicated three times.

Arabidopsis plants grown in soil for 20 days were treated with $4{ }^{\circ} \mathrm{C}$ for $48 \mathrm{~h}$ or $-10{ }^{\circ} \mathrm{C}$ for $2 \mathrm{~h}$, then the leaves of $2 \mathrm{~cm}$ diameter were used for maximal $\mathrm{Fv} / \mathrm{Fm}$ and relative EC analysis. $\mathrm{Fv} / \mathrm{Fm}$ was measured using an Imaging-PAM Chlorophyll Fluorometer (M-series, Heinz Walz GmbH, Frankfurt am Main, Germany) as described previously [31]. The percent relative EC was calculated as EC $\%=$ Post freezing EC/Post autoclaving EC $\times 100$. These experiments were replicated three times with ten plants per treatment. After the $-10{ }^{\circ} \mathrm{C}$ treatment, the plants were transferred to light $(12 \mathrm{~h}$ light $/ 12 \mathrm{~h}$ dark photoperiod) at $22^{\circ} \mathrm{C}$. The survival rates of the plants were scored visually after 2 weeks. The experiment was repeated three times and the average values were calculated. For each experiment, 5 pots from WT and three transgenic lines were used, with $4-5$ seedlings per pot.

\subsection{Net $\mathrm{Ca}^{2+}$ Flux Measurements}

Net $\mathrm{Ca}^{2+}$ flux was measured using NMT (NMT100 Series, Younger USA LLC, Amherst, MA, USA) as described previously $[25,32]$. Seven-day-old seedling root segments were immobilized in measuring solution $\left(0.1 \mathrm{mM} \mathrm{KCl}, 0.1 \mathrm{mM} \mathrm{CaCl} 2,0.1 \mathrm{mM} \mathrm{MgCl}_{2}, 0.5 \mathrm{mM} \mathrm{NaCl}, 0.3 \mathrm{mM}\right.$ 2-(N-morpholino) ethanesulfonic acid (MES), and $0.2 \mathrm{mM} \mathrm{Na}_{2} \mathrm{SO}_{4}, \mathrm{pH}$ 6.0) to measure $\mathrm{Ca}^{2+}$ flux. For sudden cold-shock treatment, transient $\mathrm{Ca}^{2+}$ flux kinetics in response to cold $\left(4{ }^{\circ} \mathrm{C}\right)$ were measured in seedling root tips. After measuring for 5-6 min at room temperature, ice-cold test buffer $\left(4^{\circ} \mathrm{C}\right)$ was quickly added to the container around the roots; $\mathrm{Ca}^{2+}$ flux was simultaneously measured for a further $10 \mathrm{~min}$. Six biological repeats were performed for each analysis.

\subsection{Statistical Analyses}

The data were analyzed via one-way analysis of variance using SPSS software (Version 19.0, SPSS Inc., Chicago, IL, USA), and statistically significant differences were calculated based on the student's $t$-test, with $p<0.05\left(^{*}\right)$ and $p<0.01\left(^{* *}\right)$ as the thresholds for significance.

Supplementary Materials: Supplementary materials can be found at http:/ / www.mdpi.com/1422-0067/19/9/ 2579/s1. Figure S1: Phenotypes of transgenic Arabidopsis and wild type (WT) seedlings under osmotic Stress; Figure S2: Expression of stress-associated genes in transgenic Arabidopsis and wild type (WT) seedlings under cold stress; Table S1: List of primers used in this study.

Author Contributions: Conceptualization, A.Z. and J.W.; Formal Analysis, A.Z. and E.L.; Investigation, A.Z., E.L., H.L. and Y.L.; Data Curation, S.F. and S.G.; Writing-Original Draft Preparation, A.Z. and E.L.; Writing-Review and Editing, J.W.; Funding Acquisition, A.Z., S.G. and J.W.

Funding: This research was funded by China Postdoctoral Science Foundation grant number 2016M601409; Natural Science Foundation of Heilongjiang Province of China grant number C2016024 and C2018021; Heilongjiang Postdoctoral Fund to Pursue Scientific Research in Heilongjiang Province of China grant number LBH-Z16024; National Key Research and Development Program of China grant number 2016YFC0500300.

Acknowledgments: This work is thanks to the sharing of Confocal laser scanning microscopy (CLSM) from Key Laboratory of Biology and Genetic Improvement of Horticultural Crops (Northeast Region), Ministry of Agriculture of China.

Conflicts of Interest: The authors declare no conflict of interest. 


\section{References}

1. Winfield, M.O.; Lu, C.; Wilson, I.D.; Coghill, J.A.; Edwards, K.J. Plant responses to cold: Transcriptome analysis of wheat. Plant Biotechnol. J. 2010, 8, 749-771. [CrossRef] [PubMed]

2. Thomashow, M.F. Molecular basis of plant cold acclimation: Insights gained from studying the CBF cold response pathway. Plant Physiol. 2010, 154, 571-577. [CrossRef] [PubMed]

3. Zhou, M.Q.; Shen, C.; Wu, L.H.; Tang, K.X.; Lin, J. CBF-dependent signaling pathway: A key responder to low temperature stress in plants. Crit. Rev. Biotechnol. 2011, 31, 186-192. [CrossRef] [PubMed]

4. Chinnusamy, V.; Zhu, J.; Zhu, J.K. Cold stress regulation of gene expression in plants. Trends Plant Sci. 2007, 12, 444-451. [CrossRef] [PubMed]

5. Zhu, J.; Dong, C.H.; Zhu, J.K. Interplay between cold-responsive gene regulation, metabolism and RNA processing during plant cold acclimation. Curr. Opin. Plant Biol. 2007, 10, 290-295. [CrossRef] [PubMed]

6. Zhu, J.K. Abiotic stress signaling and responses in plants. Cell 2016, 167, 313-324. [CrossRef] [PubMed]

7. Chen, L.; Zhong, H.; Ren, F.; Guo, Q.Q.; Hu, X.P.; Li, X.B. A novel cold-regulated gene, COR25, of Brassica napus is involved in plant response and tolerance to cold stress. Plant Cell Rep. 2011, 30, 463-471. [CrossRef] [PubMed]

8. Wathugala, D.L.; Richards, S.A.; Knight, H.; Knight, M.R. OsSFR6 is a functional rice orthologue of SENSITIVE TO FREEZING-6 and can act as a regulator of COR gene expression, osmotic stress and freezing tolerance in Arabidopsis. New Phytol. 2011, 191, 984-995. [CrossRef] [PubMed]

9. Wan, F.; Pan, Y.; Li, J.; Chen, X.; Pan, Y.; Wang, Y.; Tian, S.; Zhang, X. Heterologous expression of Arabidopsis C-repeat binding factor 3 (AtCBF3) and cold-regulated 15A (AtCOR15A) enhanced chilling tolerance in transgenic eggplant (Solanum melongena L.). Plant Cell Rep. 2014, 33, 1951-1961. [CrossRef] [PubMed]

10. Yuan, H.M.; Sheng, Y.; Chen, W.J.; Lu, Y.Q.; Tang, X.; Ou-Yang, M.; Huang, X. Overexpression of Hevea brasiliensis HbICE1 Enhances Cold Tolerance in Arabidopsis. Front. Plant Sci. 2017, 8, 1462. [CrossRef] [PubMed]

11. Steponkus, P.L.; Uemura, M.; Joseph, R.A.; Gilmour, S.J.; Thomashow, M.F. Mode of action of the COR15a gene on the freezing tolerance of Arabidopsis thaliana. Proc. Natl. Acad. Sci. USA 1998, 95, 14570-14575. [CrossRef] [PubMed]

12. Thomashow, M.F. Role of cold-responsive genes in plant freezing tolerance. Plant Physiol. 1998, 118, 1-8. [CrossRef] [PubMed]

13. Breton, G.; Danyluk, J.; Charron, J.B.; Sarhan, F. Expression profiling and bioinformatic analyses of a novel stress-regulated multispanning transmembrane protein family from cereals and Arabidopsis. Plant Physiol. 2003, 132, 64-74. [CrossRef] [PubMed]

14. Nakayama, K.; Okawa, K.; Kakizaki, T.; Honma, T.; Itoh, H.; Inaba, T. Arabidopsis Cor15am is a chloroplast stromal protein that has cryoprotective activity and forms oligomers. Plant Physiol. 2007, 144, 513-523. [CrossRef] [PubMed]

15. Thalhammer, A.; Hundertmark, M.; Popova, A.V.; Seckler, R.; Hincha, D.K. Interaction of two intrinsically disordered plant stress proteins (COR15A and COR15B) with lipid membranes in the dry state. BBA-Biomembr. 2010, 1798, 1812-1820. [CrossRef] [PubMed]

16. Thalhammer, A.; Hincha, D.K. A mechanistic model of COR15 protein function in plant freezing tolerance: Integration of structural and functional characteristics. Plant Signal. Behav. 2014, 9, e977722. [CrossRef] [PubMed]

17. Narusaka, Y.; Nakashima, K.; Shinwari, Z.K.; Sakuma, Y.; Furihata, T.; Abe, H.; Narusaka, M.; Shinozaki, K.; Yamaguchi-Shinozaki, K. Interaction between two cis-acting elements, ABRE and DRE, in ABA-dependent expression of Arabidopsis $r d 29 A$ gene in response to dehydration and high-salinity stresses. Plant J. 2003, 34, 137-148. [CrossRef] [PubMed]

18. Msanne, J.; Lin, J.; Stone, J.M.; Awada, T. Characterization of abiotic stress-responsive Arabidopsis thaliana RD29A and RD29B genes and evaluation of transgenes. Planta 2011, 234, 97-107. [CrossRef] [PubMed]

19. Lee, S.Y.; Boon, N.J.; Webb, A.A.; Tanaka, R.J. Synergistic Activation of RD29A via integration of salinity stress and abscisic acid in Arabidopsis thaliana. Plant Cell Physiol. 2016, 57, 2147-2160. [CrossRef] [PubMed]

20. Okawa, K.; Nakayama, K.; Kakizaki, T.; Yamashita, T.; Inaba, T. Identification and characterization of Cor413im proteins as novel components of the chloroplast inner envelope. Plant Cell Environ. 2008, 31, 1470-1483. [CrossRef] [PubMed] 
21. Okawa, K.; Inoue, H.; Adachi, F.; Nakayama, K.; Ito-Inaba, Y.; Schnell, D.J.; Uehara, S.; Inaba, T. Targeting of a polytopic membrane protein to the inner envelope membrane of chloroplasts in vivo involves multiple transmembrane segments. J. Exp. Bot. 2014, 65, 5257-5265. [CrossRef] [PubMed]

22. Zhou, A.; Sun, H.; Feng, S.; Zhou, M.; Gong, S.; Wang, J.; Zhang, S. A novel cold-regulated gene from Phlox subulata, PsCor413im1, enhances low temperature tolerance in Arabidopsis. Biochem. Biophys. Res. Commun. 2018, 495, 1688-1694. [CrossRef] [PubMed]

23. Shi, Y.; Ding, Y.; Yang, S. Molecular regulation of CBF signaling in cold acclimation. Trends Plant Sci. 2018, 23, 623-637. [CrossRef] [PubMed]

24. Lissarre, M.; Ohta, M.; Sato, A.; Miura, K. Cold-responsive gene regulation during cold acclimation in plants. Plant Signal. Behav. 2010, 5, 948-952. [CrossRef] [PubMed]

25. Ma, Y.; Dai, X.; Xu, Y.; Luo, W.; Zheng, X.; Zeng, D.; Pan, Y.; Lin, X.; Liu, H.; Zhang, D.; et al. COLD1 confers chilling tolerance in rice. Cell 2015, 160, 1209-1221. [CrossRef] [PubMed]

26. Shi, Y.; Gong, Z. One SNP in COLD1 determines cold tolerance during rice domestication. J. Genet. Genomics 2015, 42, 133-134. [CrossRef] [PubMed]

27. Zhang, J.Z.; Creelman, R.A.; Zhu, J.K. From laboratory to field. Using information from Arabidopsis to engineer salt, cold, and drought tolerance in crops. Plant Physiol. 2004, 135, 615-621. [CrossRef] [PubMed]

28. TMHMM Server v. 2.0. Available online: http://www.cbs.dtu.dk/services/TMHMM/ (accessed on 25 January 2018).

29. Molecular Evolutionary Genetics Analysis. Available online: http:/ /www.megasoftware.net/ (accessed on 25 January 2018).

30. Clough, S.J.; Bent, A.F. Floral dip: A simplified method for Agrobacterium-mediated transformation of Arabidopsis thaliana. Plant J. 1998, 16, 735-743. [CrossRef] [PubMed]

31. Wang, W.; Wang, Y.; Du, Y.; Zhao, Z.; Zhu, X.; Jiang, X.; Shu, Z.; Yin, Y.; Li, X. Overexpression of Camellia sinensis $\mathrm{H} 1$ histone gene confers abiotic stress tolerance in transgenic tobacco. Plant Cell Rep. 2014, 33, 1829-1841. [CrossRef] [PubMed]

32. Zhou, A.; Liu, E.; Ma, H.; Feng, S.; Gong, S.; Wang, J. NaCl-induced expression of AtVHA-c5 gene in the roots plays a role in response of Arabidopsis to salt stress. Plant Cell Rep. 2018, 37, 443-452. [CrossRef] [PubMed]

(C) 2018 by the authors. Licensee MDPI, Basel, Switzerland. This article is an open access article distributed under the terms and conditions of the Creative Commons Attribution (CC BY) license (http://creativecommons.org/licenses/by/4.0/). 